\title{
Contextualização geológica da porção sudoeste do Sistema Aquífero Boa Vista, estado de Roraima, Brasil, a partir de sondagens elétricas verticais rasas \\ Geological setting of the Southwestern Boa Vista Aquifer, State of Roraima, Brazil, from shallow vertical electric sounding
}

\author{
Lena Simone Barata Souza', Franklin Williams Silva de Carvalho' \\ Universidade Federal de Roraima. Boa Vista, Roraima, Brasil
}

\begin{abstract}
Resumo: A configuração de zonas permoporosas na porção sudoeste do Sistema Aquifero Boa Vista, no estado de Roraima, localizada no campus Paricarana, da Universidade Federal de Roraima, a partir da execução de vinte sondagens elétricas verticais, distinguiu eletricamente o comportamento do conteúdo litológico da Formação Boa Vista, amplamente distribuído na área (argilitos com $\rho_{\mathrm{a}}<1.000 \Omega$.m, arenitos com $1.000<\rho_{\mathrm{a}}<20.000 \Omega$.m e concreções lateríticas ferruginosas com $\rho>50.000 \Omega$.m). Estes resultados permitiram identificar sete padrões geoelétricos, entre os quais os padrões 1 e 3 ( $S$ W e WNW) configuraram as melhores zonas permoporosas da área, devido aos indícios de concentrações lateríticas porosas, que são circundadas por materiais argilosos de regiões com evidências quanto à presença de paleolagos e de lagos sazonais, extremamente arenosos. Os padrões 2, 4 e 6 (NW, centro-oeste, $\mathrm{N}$ e NE) representaram as zonas de moderada expressividade, pois indicaram presença de materiais areno-argilosos com até $10 \mathrm{~m}$ de profundidade. Os padrões 5 e 7, por sua vez, embora estejam amplamente distribuídos no campus (NW, NE, SE e SW), configuraram zonas permoporosas com pouco potencial aquífero, pois apontaram para maior predominância de materiais argilosos, os quais podem funcionar como camada selante, protegendo a possível zona detentora de água da contaminação superficial.
\end{abstract}

Palavras-chave: Zonas permoporosas. Sistema Aquífero Boa Vista. Sondagem elétrica vertical. Padrão geoelétrico.

Abstract: Twenty vertical electrical sounding profiles were executed during the dry season in the Paricana campus of the Federal University of Roraima. Three geoelectrical units were identified: (a) the lower resistivity unit with values $\rho_{\mathrm{a}}<1,000 \Omega$.m attributed to mudstone layers; (b) the middle resistivity unit with values 1,000 $\Omega$.m $<\rho_{2}<20,000 \Omega$.m attributed to sandstone layers; and (c) higher resistivity unit with values $\rho_{2}>50,000 \Omega$.m attributed to lateritic ferruginous concretions and/or ferruginous sandstones. From these three units, seven geoeletrictal patterns can be seen. Patterns 1 and 3 (located in the SW and WNW of the study area) configure the best permoporosity zone in the area because the pore-bearing lateritic concretions are neighboured by paleolakes and actual seasonal lakes. In addition, these patterns 1 and 3 display an extremely sand-grained character. Patterns 2, 4 and 6 (NW, mid-eastern, $N$ and NE) present moderate permoporosity because clay-bearing materials are interpreted as reaching to $10 \mathrm{~m}$ depth. Patterns 5 and 7 are attributed to a predominance of clay-bearing material in such a way that it acts as a sealant material to the aquifer protecting it from contamination from the surface.

Keywords: Permoporosity zones. Boa Vista Aquifer. Vertical electrical souding. Geoelectrical pattern.

SOUZA, L. S. B. \& F. W. S. CARVALHO, 2017. Contextualização geológica da porção sudoeste do Sistema Aquífero Boa Vista, estado de Roraima, Brasil, a partir de sondagens elétricas verticais rasas. Boletim do Museu Paraense Emílio Goeldi. Ciências Naturais 12(1): 91-107. Autora para correspondência: Lena Simone Barata Souza. Universidade Federal de Roraima. Instituto de Geociências. Departamento de Geologia. Campus Paricarana. Av. Cap. Ene Garcez, 2413 - Aeroporto. Boa Vista, RR, Brasil. CEP 69310-000 (lenabarata@yahoo.com.br). Recebido em 05/01/2017

Aprovado em 24/03/2017

Responsabilidade editorial: Fernando da Silva Carvalho Filho

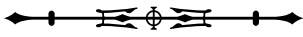




\section{INTRODUÇÃO}

A falta de água é uma dificuldade cada vez mais severa mundialmente, em virtude do consumo excessivo de água bruta, das mudanças climáticas, da poluição da água e do consumo insustentável dos recursos hídricos (Lima et al., 2011). A partir de meados do século $X X$, houve aumento desenfreado pela busca por água, fato este vinculado ao crescimento inadequado da população nos grandes centros urbanos (May, 2004; Tucci, 2008). Embora haja elevados índices de precipitação, a disponibilidade hídrica na Amazônia ocidental tem decrescido em 43\%, entre 1980 e 2007, segundo a Agência Nacional de Águas (ANA, 2013).

Os aquíferos têm demonstrando papel primordial no suprimento de água para as cidades brasileiras, onde é crescente a demanda de abastecimento, uma alternativa viável que garante o fornecimento contínuo de água para a sociedade. $\bigcirc$ uso deste recurso de forma desordenada e sem planejamento pode comprometer esta provisão, tendo em vista que os reservatórios de águas subterrâneas, uma vez contaminados, podem inviabilizar o consumo de sua água para o abastecimento humano. Desta forma, o conhecimento das propriedades físicas e/ou químicas de cada aquífero é necessário para que haja melhor planejamento e gerenciamento destas reservas, visando ao menor impacto e à sua conservação (Ellert, 2013; Rebouças, 2013; Braga, 2016).

O uso de reservatórios subterrâneos para o abastecimento em áreas urbanas e rurais tem se tornado cada vez mais constante, haja vista que as fontes superficiais, como rios e lagos, já não conseguem atender à necessidade em relação a este recurso (Gallas, 2003). Somada a este fator, a introdução de métodos geofísicos na investigação de zonas aquíferas tem se tornado mais frequente, entre os quais o levantamento elétrico, por meio da eletrorresistividade (ER), possui destaque neste quesito de investigação, permitindo otimizar custos e tempo para a detecção de regiões de maior favorabilidade hídrica na alocação de poços tubulares (Mendes \& Verma, 2002; Madrucci et al., 2005; Souza \& Verma, 2005). Os dados elétricos insinuam o contexto geológico em subsuperfície, que, combinados com dados de sensoriamento remoto, geológicos e de poços, possibilitam maior confiabilidade ao estudo realizado.

No contexto do município de Boa Vista, capital do estado de Roraima, o Sistema Aquífero Boa Vista (SABV) é responsável pelo abastecimento de $70 \%$ da população local, que, por meio de diversos poços tubulares, garante o suprimento hídrico aos boavistenses (Wankler et al., 2012). Apesar de ter grande parcela no fornecimento urbano e rural, o conhecimento deste aquífero ainda é bastante limitado, o que reforça a necessidade de estudos voltados ao estabelecimento da geometria das zonas permoporosas que o constituem. Desse modo, este estudo tem a finalidade de distinguir e de caracterizar tais zonas que demonstrem o potencial aquífero no referido município.

\section{ÁREA DE ESTUDO}

A capital Boa Vista, no estado de Roraima, limita-se a norte, com Amajari; a leste, com Bonfim e Cantá; a oeste, com Alto Alegre; e a sul, com Mucajaí. As vias de acesso à capital podem ser feitas pelas rodovias BR-174, BR-401 e RR-205. A cidade está situada à margem esquerda do rio Branco, que é o principal manancial hídrico regional; entre seus afluentes, destaca-se o rio Cauamé (Figura 1A). A parte urbana boavistense, segundo Souza et al. (2010), é subdividida hidrograficamente em seis microbacias: igarapés Caranã, Caxangá, Grande, Mirandinha, Pricumã e Frasco (Figura 1B). A porção noroeste do perímetro urbano desta cidade é o foco da presente pesquisa, realizada na área do campus Paricarana, da Universidade Federal de Roraima (UFRR). Esta área, por sua vez, é cortada pelo igarapé Frasco, podendo ser, ocasionalmente, um dos agentes contribuidores para as zonas permoporosas ao SABV.

Foi realizado estudo eletrorresistivo nos perímetros da UFRR (Figuras 1B-1C). A área abrange cerca de 1 km², sendo possível observar a presença de paleolagos; também se verificou que nos contornos da região em estudo existe maior influência da microbacia do igarapé Frasco, onde sua drenagem alimenta alguns lagos sazonais. 
$2 \frac{\sqrt{1}}{7}$

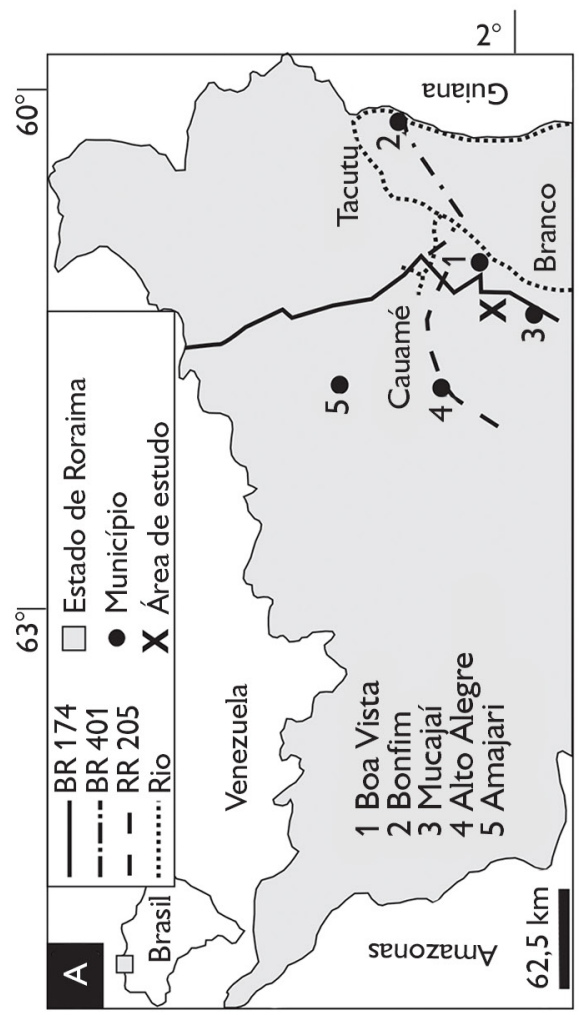

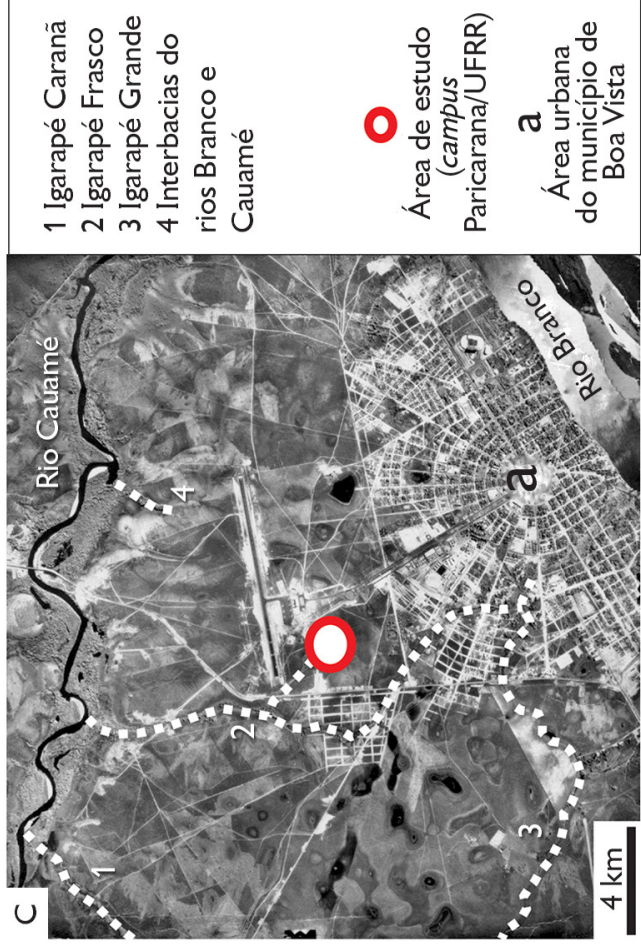

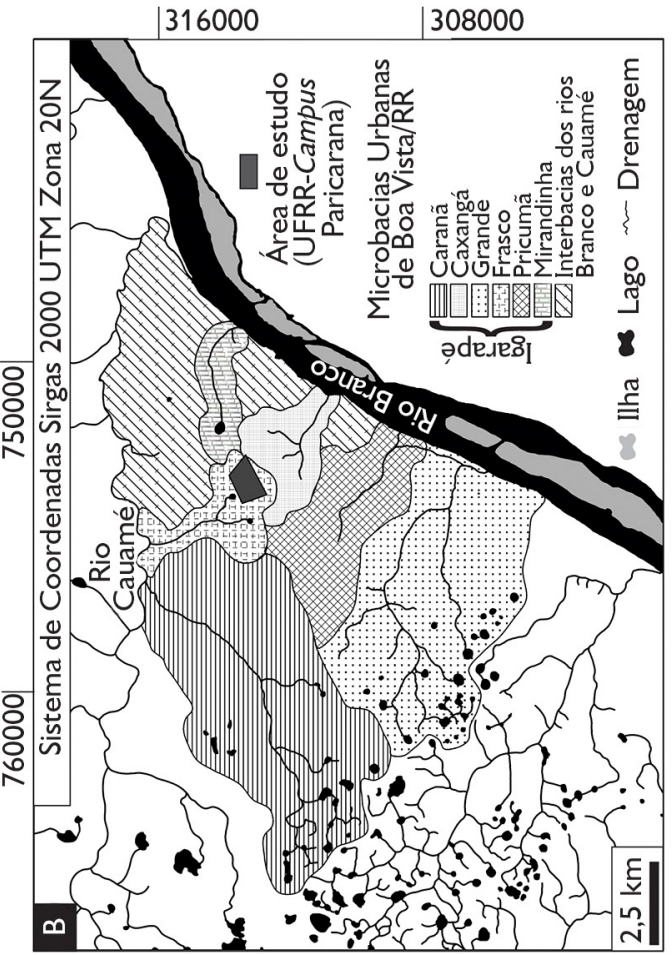

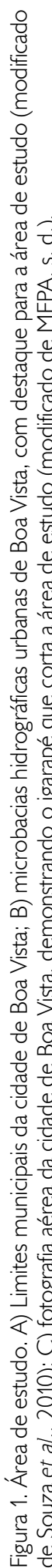

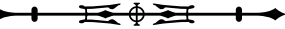


Na área de estudo, o nível freático tem, em média, 6,3 m de profundidade, apresentando, na região do campus, nível de 3,5 m (Ávila, 2007). No inverno, esta configuração muda e o nível chega a aflorar em algumas porções.

\section{SISTEMA AQUÍFERO BOA VISTA (SABV)}

A gama de informações sobre o Sistema Aquífero Boa Vista é extremamente baixa e pontual. A Agência Nacional de Águas (2013) o coloca nos países da Guiana (40\%) e no Brasil (60\%). Na porção brasileira, está localizado no extremo Norte. Wankler et al. (2012) retratam o sistema como dominantemente intergranular, ocorrendo na maior parte do município de Boa Vista (Figura 2). A espessura dele varia de $15 \mathrm{~m}$ (Reis et al., 2003) até $120 \mathrm{~m}$ (Vaz et al., 2007). Geologicamente, é constituído pelas formações Serra do Tucano (Cretáceo), Boa Vista (Terciário), Areias Brancas (Quaternário) e por depósitos fluviais coluvionares e aluvionares (Quaternário). A Formação Boa Vista alonga-se por toda a extensão do aquífero e, consequentemente, perfaz todo o município. Ela é caracterizada por ambiente sedimentar flúvio-aluvionar, composta por intercalações de argilitos, siltitos, arenitos, conglomerados e concreções lateríticas, apresentando espessura média no município e no entorno de cerca de $40 \mathrm{~m}$. Rochas basálticas e andesíticas associadas ao Complexo Vulcânico Apoteri do Triássico compõem a base do aquífero e da deposição dos sedimentos mesozoicos e cenozoicos na área do Hemigraben Tacutu (CPRM, 2002; Reis et al., 2003).

Perfurações de poços na área de Boa Vista demonstraram gradação normal sedimentar (areias grossa e fina, argila e silte), sendo a porção leste predominantemente arenosa e a oeste, dominada por camadas argilosas. A associação desta sedimentação à vazão específica (média de $3,5 \mathrm{~m}^{3} / \mathrm{h} / \mathrm{m}$ ) mostrou maior produtividade do aquífero na região leste em comparação ao centro-oeste do município. Essa anisotropia dá ao aquífero caráter majoritariamente livre a semiconfinado ou, ainda, confinado (CPRM, 2002).

Segundo a CPRM (2002), as características químicas do aquífero na área urbana de Boa Vista são de águas

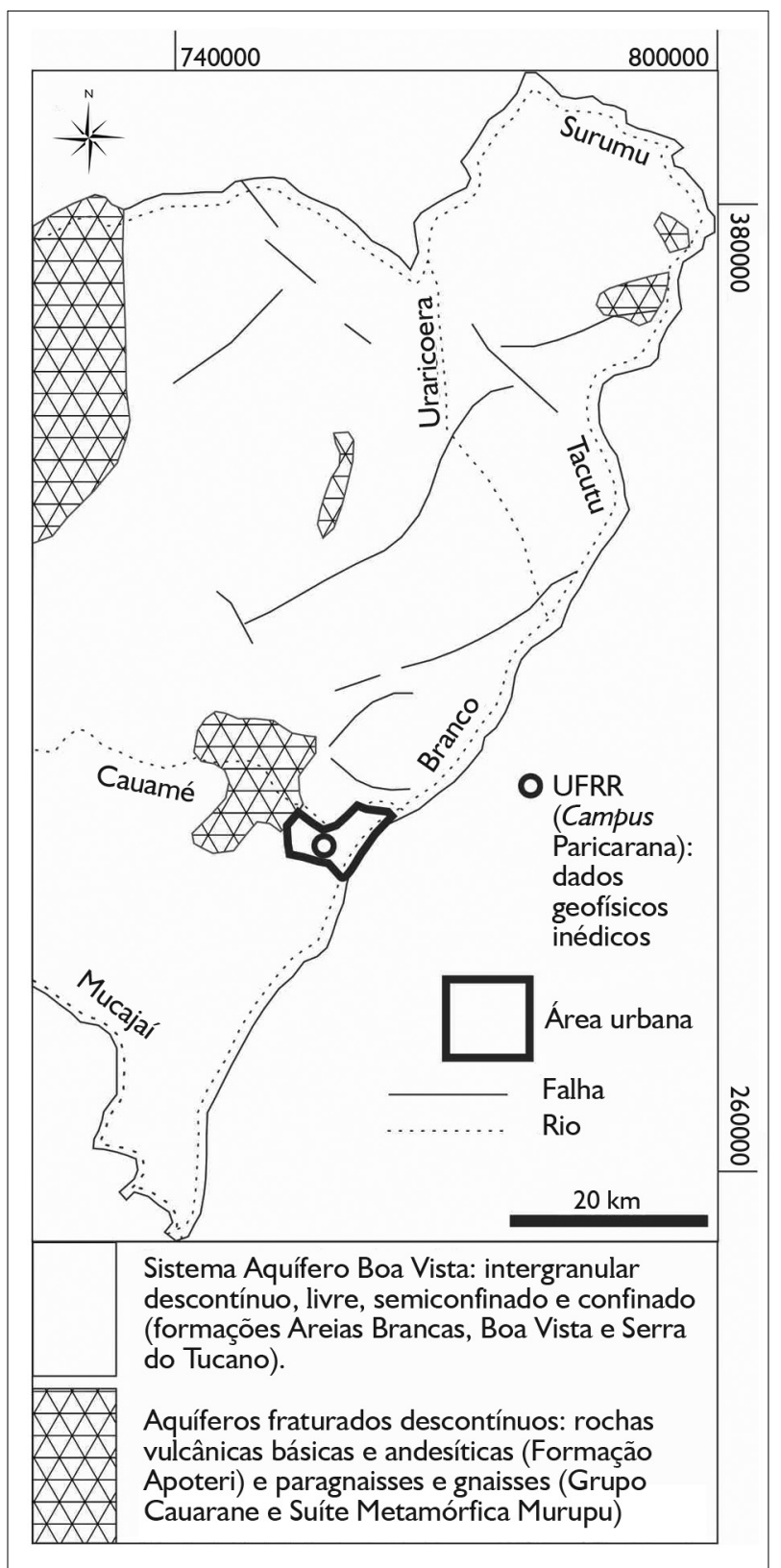

Figura 2. Sistema Aquífero Boa Vista (SABV) no município de Boa Vista (modificado de Wankler et al., 2012).

cloretadas sódicas, ácidas, com pH de 3,6-4,9, e condutividade elétrica variando de 8,3-119,5 $\mu \mathrm{S} / \mathrm{cm}$. Valores superiores a $50 \mu \mathrm{S} / \mathrm{cm}$ foram registrados na zona leste, a qual possui maior densidade populacional. Tais valores são indicativos de contaminação, em virtude de 
infiltração de águas servidas e das fossas domésticas para o aquífero sotoposto. $\bigcirc$ nível freático deste sistema é elevado, aumentando, portanto, sua vulnerabilidade à contaminação. É válido mencionar que na zona leste foram registrados os maiores valores de nitrato ( $>2 \mathrm{mgN} / \mathrm{L}$ ), mesmo que com resultados abaixo do máximo permitido (10 mgN/L). A potencialidade à contaminação das águas subterrâneas inclui, ainda, as zonas sul e sudoeste da cidade, uma vez que ali o subsolo mostra-se permeável, sendo que o lençol freático é mais raso no período de estiagem (1,4-4,0 m de profundidade) (Ávila, 2007).

\section{MATERIAIS E MÉTODOS}

O mapeamento das zonas permoporosas na área do campus Paricarana, da UFRR, pertencentes ao SABV em sua porção SW, tomou como principal ferramenta o ensaio eletrorresistivo (ER), além das imagens de sensoriamento remoto (SR), de dados litológicos de poço e da geologia local. Os produtos de SR empregaram imagens do satélite Landsat 8, disponibilizados pelo Serviço Geológico americano (dos Estados Unidos) (USGS, s. d.) e pelo software Google Earth Pro. As imagens Landsat foram adquiridas em 15 de setembro de 2014, georreferenciadas e corrigidas em relação à cena 232/058 (órbita/ponto). Os produtos das imagens resultaram da composição de bandas Red Green Blue-RGB (R4G3B2), com resolução espacial de 30 m, e da fusão das bandas R4G3B2, com a banda 8 (pancromática), derivando na resolução espacial de $15 \mathrm{~m}$. Os produtos do Google Earth Pro consistiram nas imagens feitas em janeiro de 2015. O processamento das imagens de SR ocorreu com auxílio dos softwares ArcGis e ENVI.

A coleta dos dados geofísicos na região do campus Paricarana tomou como base a técnica de levantamento de ER, a partir da sondagem elétrica vertical (SEV), com arranjo Schlumberger, fazendo-se uso do aparelho do resistivímetro Megger Biddle 63241 Earth Tester (Null Balance), pertencente ao Instituto de Geociências, da Universidade Federal do Amazonas (UFAM). Esta técnica foi aplicada na área de estudo em razão da existência de terrenos sedimentares, sendo amplamente eficiente no estudo de aquíferos (Mendes \& Verma, 2002; Souza \& Verma, 2005).

O desenrolar da coleta foi feito de modo sistemático, a fim de se alcançar um levantamento correto, observando a integridade dos cabos utilizados e as distâncias entre os eletrodos, cujos espaçamentos foram regularmente distribuídos em escala métrica. $\bigcirc$ dispositivo de medida é composto de dois eletrodos metálicos de corrente (A e B), ambos conectados por cabos a uma fonte de corrente elétrica contínua ou alternada, de baixa frequência, disposta em série a um amperímetro, e por dois eletrodos de potencial ( $\mathrm{M}$ e $\mathrm{N}$ ), conectados em série a um voltímetro. Os quatros eletrodos são cravados no solo (Figura 3, A-B). Em seguida, mede-se a diferença de potencial $(\Delta V)$ natural/espontâneo do terreno, para estabilização do equipamento, até zerá-lo completamente. Após a estabilização, mede-se o valor de resistência elétrica $(R)$ através da fórmula $R=\Delta V / I$, com medida em $\Omega$ (sendo $\Delta \mathrm{V}=$ diferença de potencial elétrico entre os eletrodos de potencial e I = corrente contínua aplicada entre os eletrodos de corrente), a qual é anotada na ficha de campo para auxiliar no cálculo da resistividade aparente $\left(\rho_{\mathrm{a}}\right)$, utilizando-se, para isto, a equação $\rho_{\mathrm{a}}=\mathrm{k} \cdot \mathrm{R}$, dada em $\Omega$.m (onde $\mathrm{k}=$ coeficiente geométrico dependente do arranjo dos eletrodos na superfície e $R$ $=$ resistência elétrica). Ao término deste cálculo, foram plotados os valores de $\rho_{\mathrm{a}}$ na ficha, configurando-se, assim, o esboço da curva de campo (em escala bi-log) para uma avaliação inicial do comportamento do terreno (camadas resistivas e/ou condutivas). Ruídos culturais locais foram cuidadosamente registrados, com o intuito de avaliar a sua interferência nas informações obtidas (tubulações de ferros, fiações elétricas/telefônicas).

A técnica foi baseada na aquisição de vinte SEV, com distâncias mínimas entre os eletrodos de corrente igual a $2 m(A B / 2=1 m)$ e a máxima correspondente a $48 m(A B / 2=24 m)$. As $\rho_{a}$ foram processadas usando-se o programa de inversão IPI2Win, desenvolvido pela GEOSCAN-M Ltd. No entanto, devido à rasa 


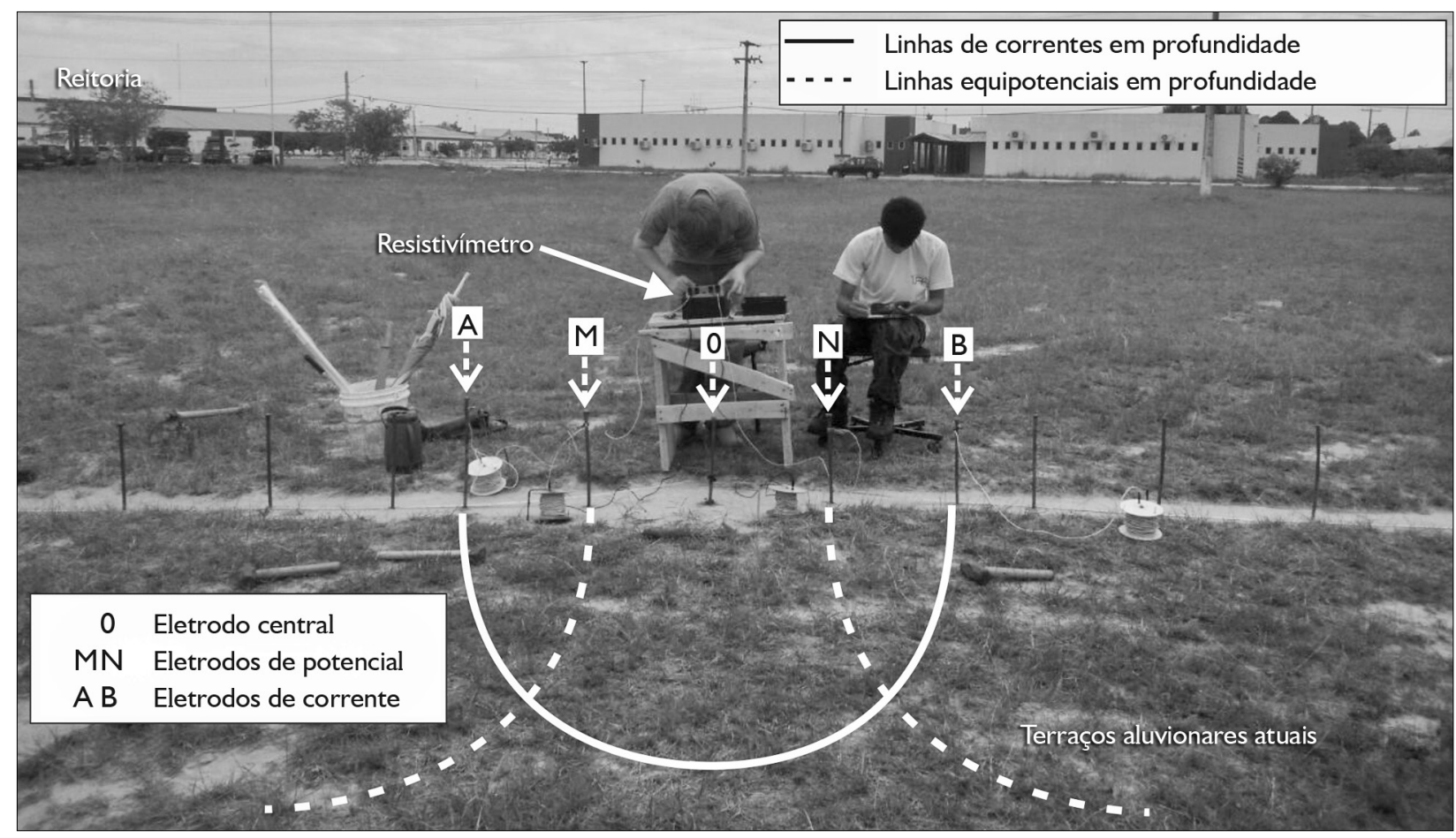

Figura 3. Coleta de dados em campo exemplificando o dispositivo de leitura Schlumberger.

profundidade investigada, não foram feitas inversões das curvas de $\rho_{\mathrm{a}}$, mas os valores de resistividade elétrica serviram de base para fornecer uma visualização geoelétrica local da distribuição litológica dos depósitos do Terciário e do Quaternário (Formação Boa Vista e terraços aluvionar e coluvionar atuais), além de possibilitar inferir, mesmo que de forma hipotética, sobre a expressão das zonas permoporosas do SABV em subsuperfície.

\section{CONTEXTUALIZAÇÃO GEOÉLETRICA}

O mapeamento geofísico executado na porção noroeste do SABV, região do campus de Paricarana, da UFRR, distinguiu eletricamente sete padrões geoelétricos, em função da similaridade do comportamento da maioria das curvas de resistividade, além da analogia moderada dos valores médios de $\rho_{\mathrm{a}}$ e, por fim, da localização da SEV (Figura 4). A distinção destes padrões implica a disposição e a dinâmica das possíveis zonas permoporosas na porção sudoeste do SABV.

\section{PADRÕES GEOELÉTRICOS}

\section{Padrão 1 (SEV 1)}

Presente na região SW, próximo ao Complexo do Insikiran (Figura 4). A sondagem alcançou $24 \mathrm{~m}$ de profundidade e valores de $\rho_{a}$ elevados, variando de 7.000 a $62.000 \Omega$.m. De início, entre 1,0-1,8 m, o gráfico apresenta convexidade sem denotar muita suavidade; posteriormente, de 1,8-10 m de profundidade, é visível o crescimento progressivo muito proeminente dos valores de resistividade, atingindo pico de $62.790 \Omega$.m. Em seguida, de 10-13 m, percebe-se queda bastante acentuada, para valores de $10.614 \Omega$.m, com variação em torno de $52.176 \Omega$.m; em um último momento, de 13-24 m, o gráfico demonstra novamente variação, apresentando crescimento de 13-18 m (10.000 s $\rho_{\mathrm{a}} \leq 20.000 \Omega \mathrm{m}$ ); com as profundidades superiores a $18 \mathrm{~m}$, a $\rho_{\mathrm{a}}$ decai e atinge valores de $16.000 \Omega$.m (Figura 5A).

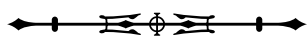




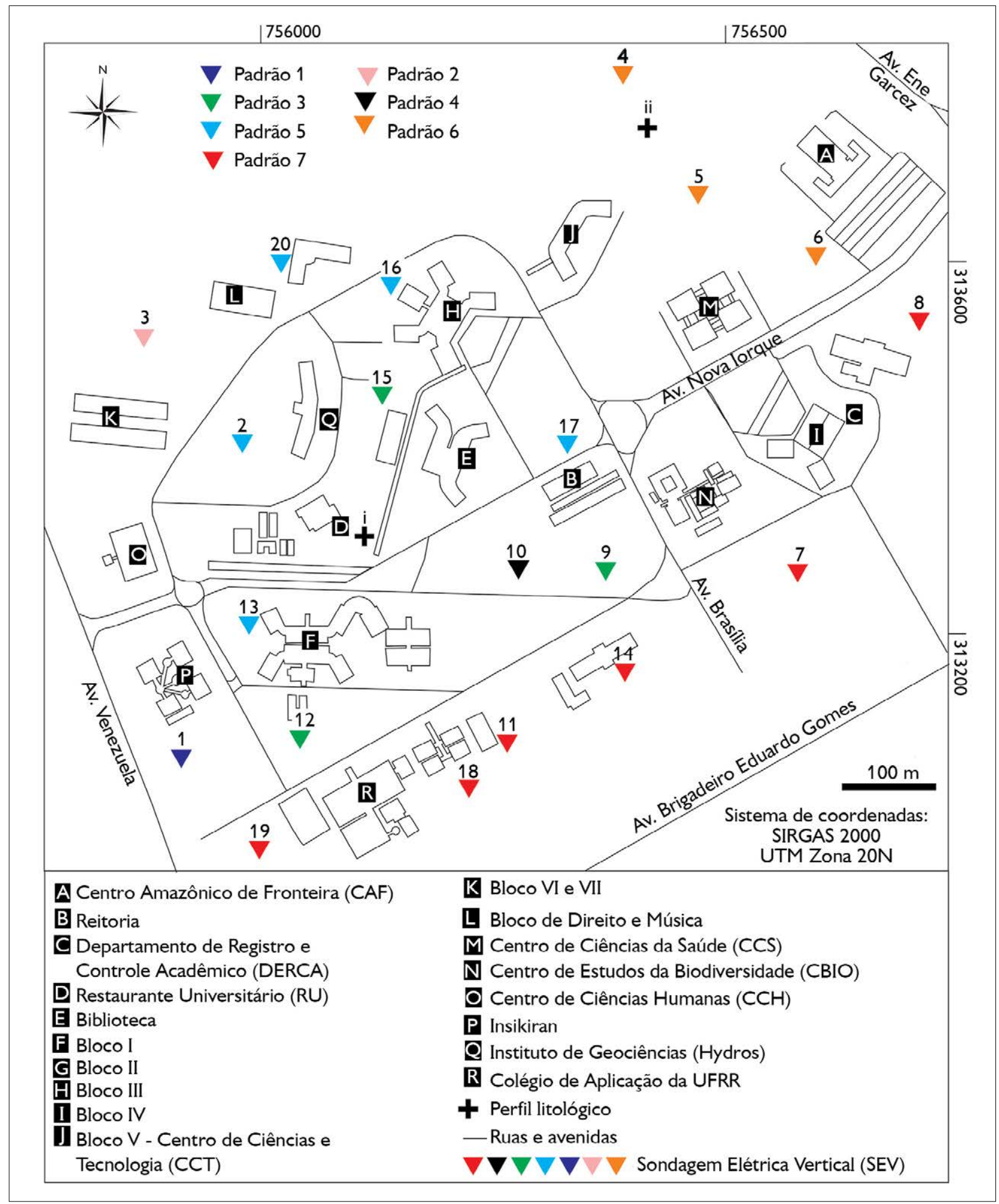

Figura 4. Mapa de ponto das SEV (campus Paricarana/UFRR).

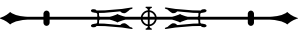


quadro elétrico do padrão 1 oferece analogia aos depósitos sedimentares da Formação Boa Vista, a qual é constituída basicamente por sedimentos arenosos com cimento argiloso, intercalados a camadas conglomeráticas, sendo que em toda a sequência sedimentar são encontrados níveis lateríticos (Beserra Neta \& Tavares Junior, 2008; Pinto et al., 2012; Reis et al., 2003). Assim, os respectivos valores de resistividade demonstraram que, nas camadas inferiores a $10 \mathrm{~m}$ de profundidade, há granodecrescência dos sedimentos arenosos (arenitos e siltitos), indicando crescimento desses valores. É importante salientar que os maiores valores de resistividade registrados no campus foram deste padrão (em torno de $60.000 \Omega$.m). Esta condição elétrica pode ser relacionada ao arenito ferruginoso/ concreções lateríticas ferruginosas observado no mapeamento geológico local, bem como a seixos milimétricos e dessimétricos dispostos in situ e/ou rolados (Figura 6A).

O paleossolo laterítico caracterizado eletricamente na região nordeste do estado do Pará apresentou elevado valor de resistividade elétrica, devido à alta porosidade e por se encontrar fraturado (Souza, 2010; Souza et al., 2013). Esta condição física foi também observada nas concreções lateríticas do campus Paricarana. $\bigcirc$ fraturamento deste material está relacionado às reativações do sistema Hemigraben do Tacutu, por falhamentos transcorrentes e normais, refletidos na presença de zonas de concreções lateríticas sobre as rochas das formações Apoteri e Boa Vista (Pinto et al., 2012). Assim, o processo da laterização sobre as rochas pré-existentes consolidou as concreções destas formações, dando, consequentemente, um caráter altamente poroso, corroborando os altos índices de resistividade, associados ao padrão geolelétrico 1. Em relação à expressiva queda dos valores de $\rho_{\mathrm{a}}$, entre 10-13 m, infere-se que seja uma possível franja capilar, denotando a presença de sedimentos extremamente arenosos a esta profundidade. Essa especulação é amplamente difundida na literatura (por exemplo, em Braga, 2016).

\section{Padrão 2 (SEV 3)}

Localizado na porção NW, próximo ao Bloco VII (Figura 4). A profundidade máxima de alcance da sondagem foi de 5,5 m. O gráfico gerado a respeito deste padrão apresenta geometria serrilhada não contínua e com tendência decrescente, com $\rho_{\mathrm{a}}$ elevadas, variando de 7.000-19.000

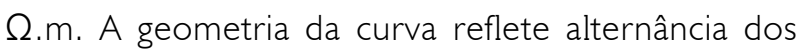
valores de $\rho_{a}$, ora cresce e ora diminui. De início, nas profundidades de 1,0-1,3 m, observa-se variação de 8.168 $\Omega . m$ (iniciando em $19.614 \Omega . m$ e caindo para 11.446 $\Omega$.m). No intervalo de 1,8-3,2 m, há diminuição do valor de $\rho_{\mathrm{a}}$, aspecto observado também em profundidade de $5,5 \mathrm{~m}$, situação em que a leitura atingiu valores inferiores a 8.000 S.m (Figura 5B). Segundo Kearey et al. (2009), materiais argilosos (argilito) e arenosos (siltitos e arenitos) mostram resistividades baixa e alta, respectivamente. Desta forma, podemos deduzir que o comportamento serrilhado da curva reflete a intercalação de argilitos e arenitos, os quais são predominantes na Formação Boa Vista.

\section{Padrão 3 (SEV 15, 9 e 12)}

Localizado nas faixas WNW (SEV 15) e SW (SEV 9 e 12) (Figura 4), destaca-se por apresentar resistividades elevadas e constantes, com valores em torno de 7.000$10.000 \Omega$.m. Nem todas as sondagens que estão contidas neste padrão atingiram as profundidades máximas de 24 m, exceto pela SEV 9; já as SEV 12 e 15 alcançaram profundidades correspondentes a $4,2 \mathrm{~m}$ e $10 \mathrm{~m}$, respectivamente. Entre as três sondagens realizadas, as SEV 9 e 12 foram as que exibiram comportamento elétrico com mudanças pouco acentuadas, onde demonstram alternância decrescente das $\rho_{\mathrm{a}}$ a profundidades de 1,0-4,2 m, com variações em torno de $3.000 \Omega$.m, sendo que a geometria da SEV 9 mostra concavidade bastante suave, entre 4,2-24 m. No entanto, a curva da SEV 15 tem comportamento predominantemente retilíneo quando exposta à profundidade de 1,0-7,5 m; somente aos 7,5$10 \mathrm{~m}$ expõe queda de resistividade pouco proeminente, saindo de $8.679 \Omega$.m para $5.375 \Omega$.m (Figura 5C). 
Em geral, o conteúdo elétrico do padrão 3 tem comportamento levemente retilíneo, com variações de $\rho_{\mathrm{a}}$ discretas ao longo da profundidade. Os valores de resistividade denotam caráter relacionado a materiais resistivos típicos de sedimentos arenosos (Figura 6B). Ávila (2007), por meio dos trabalhos de perfurações de poços realizados na cidade de Boa Vista, identificou maior predominância de níveis arenosos em relação aos argilosos no campus Paricarana; o presente mapeamento elétrico confirma isto.

\section{Padrão 4 (SEV 10)}

Posicionado na região centro-oeste. Nele, as resistividades aparentes ficaram entre 2.000-9.000 $\Omega$.m e a profundidade máxima do estudo foi de $13 \mathrm{~m}$. O delineamento da curva de $\rho_{\mathrm{a}}$, entre 1,0-4,2 $\mathrm{m}$, demonstra forma serrilhada decrescente, saindo de 9.424-2.013 $\Omega$.m. Posteriormente, de 4,2-13 m, o gráfico tem crescimento progressivo bastante suave, atingindo 8.480 $\Omega$.m (Figuras 4 e 5D). Apesar de este padrão estar intimamente posicionado na região do padrão 3, existem duas situações que impossibilitaram agrupar a SEV 10 nele. A primeira diz respeito à geometria serrilhada da curva (profundidades $\leq 4,2 \mathrm{~m}$ ), e a segunda, aos valores de resistividade de $7.000 \leq \rho_{a} \leq 10.000$, que são peculiares às sondagens do padrão 3 .

A variação inicial dos valores de resistividade nas profundidades inferiores a 4,2 m mostra provável intercalação de materiais arenosos e argilosos. Subsequentemente, o crescimento das $\rho_{\mathrm{a}}$ em profundidades maiores que 4,2 m mostra predominância de material com características mais arenosas. Estas implicações estão embasadas na literatura geofísica, através das observações feitas, por exemplo, por Parasnis \& Orellana (1970), Parasnis (1971) e Braga (2016). O comportamento geofísico deste padrão sugere a ciclicidade de deposição de sedimentos arenosos e argilosos (Figura 6B) em ambiente flúvio-aluvionar, amplamente distribuída ao longo da Formação Boa Vista (Reis et al., 2003; Wankler et al., 2012).
Padrão 5 (SEV 2, 13, 16, 17 e 20)

Presente nas zonas NW (SEV 2, 16, 17 e 20) e SW (SEV 13) (Figura 4), o padrão apresenta $\rho_{\text {a }}$ em torno de 800-6.000 $\Omega$.m, e o cume extremo da profundidade investigada foi de 24 m, com exceção apenas da SEV 13, que atingiu 18 $m$. As SEV 2 e 16 possuem $\rho_{a}$ elevadas em relação à SEV 20, já as SEV 13 e 17 são as mais baixas (Figura 5E).

Ao analisarmos as cinco sondagens, a SEV 20 apresenta leve concavidade, com valores entre 1,02,4 $\mathrm{m}$ de profundidade. A partir de 2,4 m até $24 \mathrm{~m}$, observa-se decrescimento suave da $\rho_{\mathrm{a}}$, de $5.012 \Omega$.m

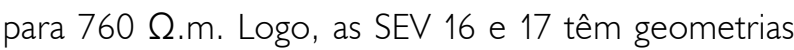
similares, ambas iniciando na faixa de $4.000 \Omega$.m, a 1,0 $\mathrm{m}$ de profundidade, e terminando em $3.000 \Omega$.m, aos $24 \mathrm{~m}$. Vale destacar que a SEV 17 tem convexidade mais resistiva na faixa de 1,8-18 $\mathrm{m}$, onde as $\rho_{\mathrm{a}}$ chegam a valores em torno de $6.000 \Omega$.m, enquanto a SEV 16 apresenta formato convexo menos acentuado no intervalo de 2,4-18 m, cuja resistividade aparente

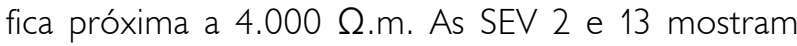
geometrias semelhantes, no entanto os valores de $\rho_{a}$ na SEV 13 são moderadamente elevados, com médias entre 2.946-5.713 $\Omega . m$. Todavia, a SEV 2 fica com médias de 2.462-4.395 $\Omega$.m. A SEV 13, portanto, ainda possui comportamento mais acentuado em relação à SEV 2 (Figura 5E).

De modo geral, o padrão 5 apresenta o formato que lembra uma cunha em direção ao norte da área, sendo seus flancos associados às SEV 13 e 17, as quais são mais resistivas às primeiras profundidades, inferindo o comportamento arenoso ao material; à medida em que aumenta a profundidade de investigação, a resistividade diminui, supondo-se a presença de material areno-argiloso (Figura 6B). Nas proximidades da extremidade da cunha, referentes às SEV 2 e 16, denotam-se resistividades medianas, sugerindo-se que o material tenha caráter areno-argiloso em todas as profundidades, isto é, de 1,0-24 m. A SEV 20 representa a charneira da cunha, onde foi discriminado o menor valor de $\rho_{\mathrm{a}}(760 \Omega$.m), na 
profundidade de $24 \mathrm{~m}$. Este valor pode estar relacionado à proximidade com antigas planícies de inundação do igarapé Frasco, que tem caráter sazonal (Figura 6C). Assim, esta feição geomorfológica engloba sedimentos que variam a granulometria de fina a grosseira, ou seja, materiais argiloso e arenoso (Suguio, 1980; Grotzinger \& Jordam, 2013).

É de suma importância retratar ainda que o perfil litológico construído próximo ao restaurante universitário $(R U)$ do campus demonstra que, até $3 \mathrm{~m}$ de profundidade, o material predominante é de granulometria de areia, ora argilosa ora siltosa, cuja a porção basal é marcada pela presença de nódulos avermelhados (resquícios de concreções lateríticas ferruginosas), que distam de 10 a $15 \mathrm{~cm}$ uns dos outros (Figuras 7A e 7B). Essa litologia corrobora a ideia de que pelo menos até os primeiros $3 \mathrm{~m}$ há material com características resistivas, conforme identificado nos dados de sondagem elétrica. A partir desta profundidade, o nível do lençol freático começa a aflorar (Figuras 7A e 7C). Logo, o comportamento elétrico descrito e o aparecimento do nível d'água comprovaram que o subsolo é permeável e que, em períodos de estiagem, a água começa a brotar em torno de $4 \mathrm{~m}$ de profundidade, legitimando os dados de Ávila (2007), mas fazendo uso de metodologias indiretas de investigação.

\section{Padrão 6 (SEV 4, 5 e 6)}

Este padrão está localizado no extremo norte e na região nordeste (SEV 4, 5 e 6, com $\rho_{\mathrm{a}}$ entre 2.000-6.000 $\Omega . m$ ) da área estudada. As SEV 4 e 6 atingiram $24 \mathrm{~m}$ de profundidade, e a SEV 5 foi investigada até 7,5 m de profundidade (Figuras 4 e 5F). Os gráficos das SEV 4 e 6 têm geometrias semelhantes, iniciando com $\rho_{\text {a }}$ na faixa de $4.000 \Omega$.m; posteriormente, as curvas mostram formatos côncavos, sendo que, na SEV 4, são mais acentuadas nos intervalos de 1,3-7,5 m de profundidade e, na SEV 6, nos intervalos de 1,8-4,2 m. Ambas configuram quedas acentuadas, na SEV 4 ocorre aos 7,5-10 m, com valores entre 3.530-1.067 $\Omega . m$, e na SEV 6 esse declínio é observado entre 4,2-5,5 m, com $\rho_{\mathrm{a}}$ indo de 3.202-1.518 $\Omega$.m. Sucessivamente, nota-se o aumento progressivo dos valores de resistividade atingindo

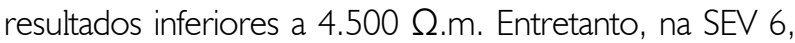
esta progressão não é tão expressiva a partir dos $13 \mathrm{~m}$. A SEV 5 evidencia queda abrupta nas profundidades inferiores a 2,0 m, com $\rho_{\mathrm{a}}$ entre 6.715-1.796 $\Omega . \mathrm{m}$. Em seguida, a curva apresenta convexidade no intervalo de profundidade entre 1,8-5,5 $\mathrm{m}$ e, aos 7,5 $\mathrm{m}$ tende a elevar os valores de resistividade, finalizando em $4.253 \Omega$.m.

Analisando os comportamentos das curvas de resistividade, verificou-se a alternância de níveis argiloso e arenoso, com exceção da SEV 5, onde essa variação corresponde a uma porção mais arenosa e, consequentemente, mais resistiva, com valores alcançando $6.000 \Omega$.m. A intercalação desses sedimentos está associada aos intervalos (ora resistivo, ora condutivo) ao longo das profundidades geoelétricas investigadas, fato confirmado através do poço tubular localizado no extremo norte da área de estudo (Figura 7D). Logo, o ensaio elétrico executado ratifica a natureza litológica argilosa e arenosa do SABV descrito por Neres \& Wankler (2012) e Wankler et al. (2012).

\section{Padrão 7 (SEV 7, 8, 11, 14, 18 e 19)}

Presente nas regiões NE, SE e SW, representado pelas SEV 7, 8, 11, 14, 18 e 19, as quais tiveram alcance de $24 \mathrm{~m}$ de profundidade e registraram os menores valores de $\rho_{\mathrm{a}}$ entre todos os padrões geoelétricos da área estudada (8004.000 S.m) (Figura 4). As curvas das SEV 7, 11 e 18 têm geometria incipientemente serrilhada, onde tal oscilação é de $500 \Omega$.m, sendo mais perceptível na SEV 11, em todas as profundidades investigadas. Contudo, as SEV 7 e 18 apresentam suave retilinearidade nas profundidades 4,218 m e 2,4-24 m, e resistividade com média de $100 \Omega$.m e $200 \Omega . m$, respectivamente. Na SEV 8, são verificados dois momentos de oscilação da curva nas profundidades 1,0-1,8 m e 5,5-13 m, correspondendo aos picos máximos de resistividade de $2.545 \Omega$.m e $3.139 \Omega$.m. Entre esses picos, é notória a planaridade do gráfico, com valores de $\rho_{\mathrm{a}}$ na faixa de $2.000 \Omega$.m. O comportamento inicial do gráfico da SEV 14 tem o aspecto planar até a profundidade de

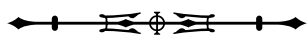


1,8 m, com $\rho_{\mathrm{a}}$ de 825-780 $\Omega$.m. Após esta profundidade, a curva registra escalonamento de 1,8-18 m, com cimos de $1.038 \Omega . m, 1.698 \Omega$.m e $1.522 \Omega$.m. O cimo máximo da SEV 19 foi observado na profundidade de $7,5 \mathrm{~m}$, com $\rho_{\mathrm{a}}$ de $7.025 \Omega$.m, decrescendo para 2.701 $\Omega . m$ até $24 \mathrm{~m}$. É importante enfatizar a idiossincrasia inicial desta sondagem, pois tem tendência côncava até 4,2 m e $\rho_{\mathrm{a}}$ de

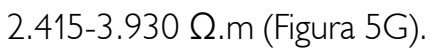
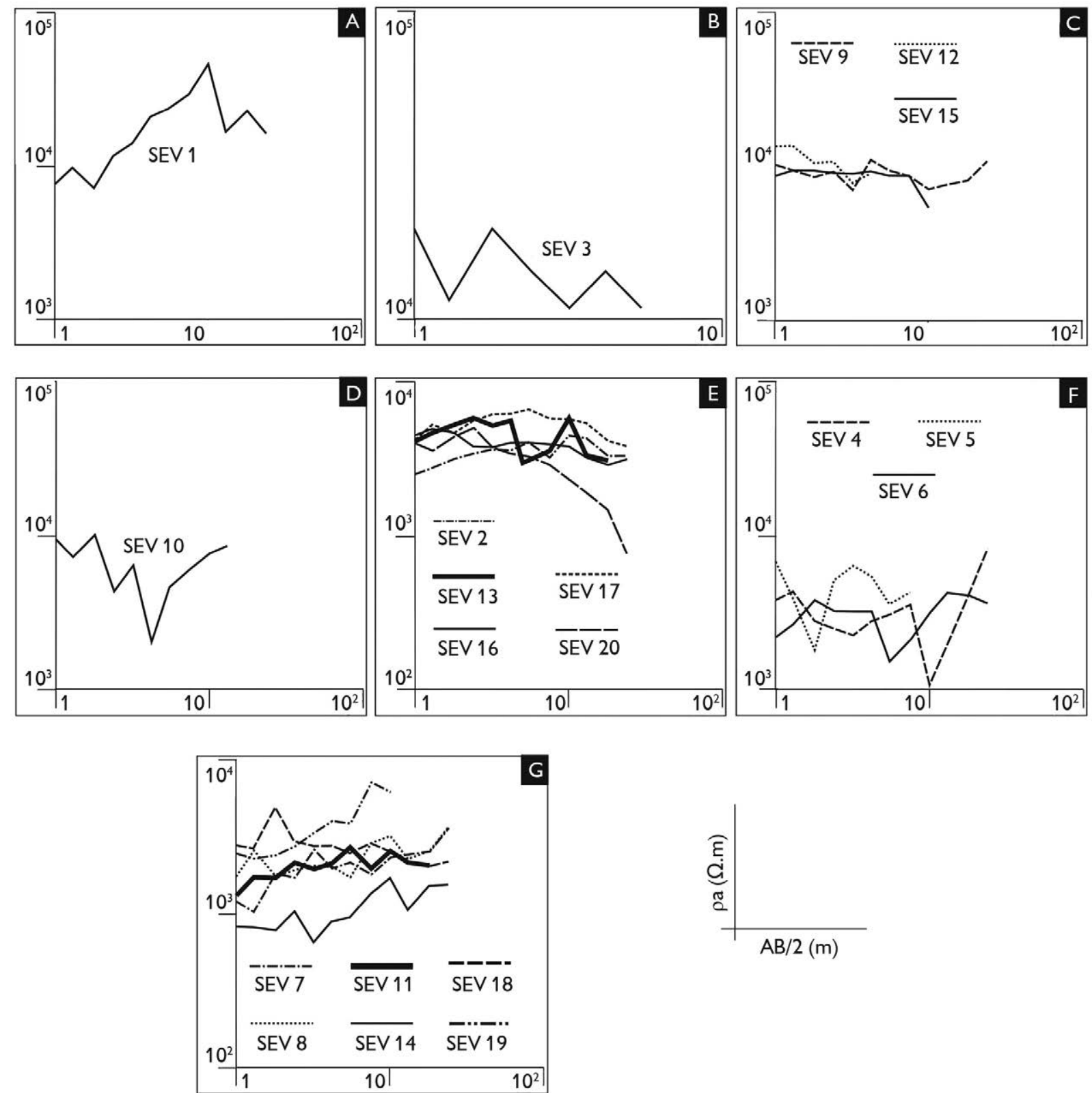

Figura 5. Curvas de resistividade elétrica. Padrões geoelétricos: A) padrão 1; B) padrão 2; C) padrão 3; D) padrão 4; E) padrão 5; F) padrão 6; G) padrão 7.

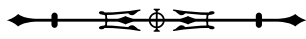




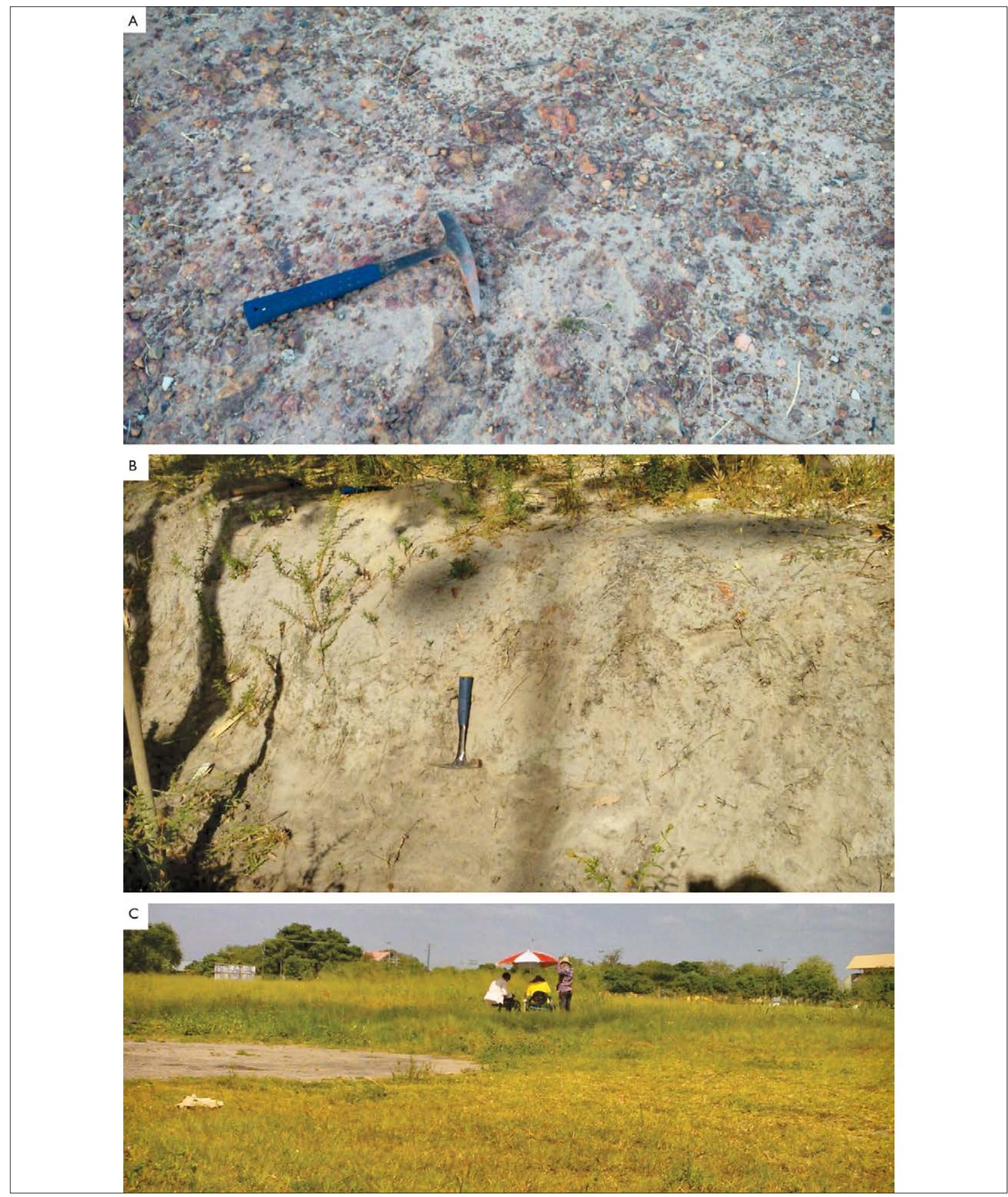

Figura 6. Fotos dos aspectos geológicos de campo: A) concreções lateríticas in situ e/ou roladas; B) sedimentos arenosos típicos da Formação Boa Vista e/ou terraços aluvionares recentes; C) planície de inundação do igarapé Frasco. 


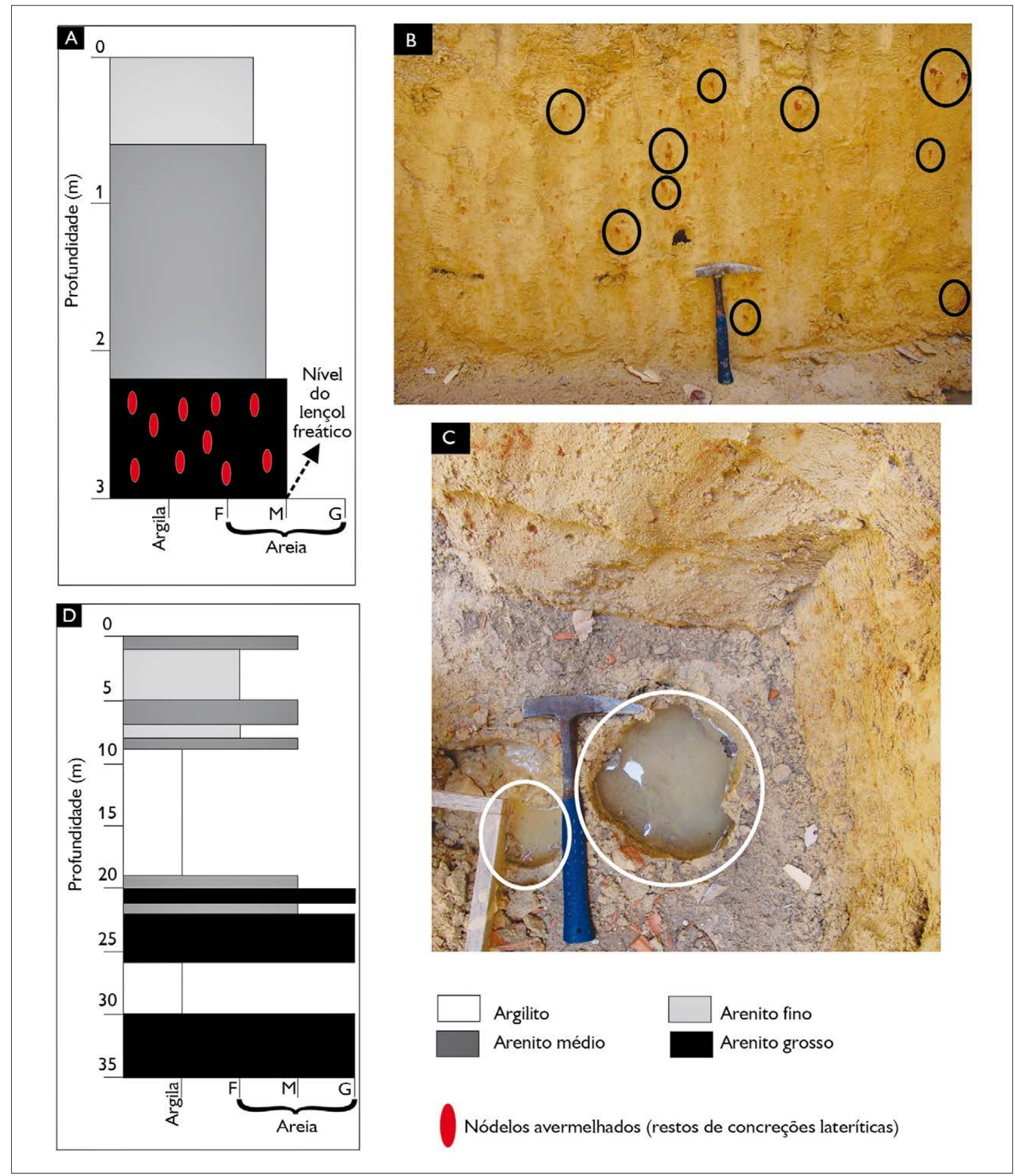

Figura 7. Perfis litológicos: A) perfil 1 localizado nos entornos do restaurante universitário, relacionado ao padrão geoelétrico 5; B) foto de detalhe dos nódulos avermelhados (círculos pretos); C) foto do nível do lençol freático aflorante em período de estiagem (círculos brancos); D) dados de poço do perfil 2 (modificado de Neres \& Wankler, 2012) próximo ao padrão geoelétrico 6. Ver localização dos perfis na Figura 4.

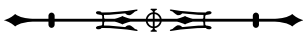


A partir da investigação das sondagens que compõem o padrão 7, foi possível observar que nas SEV 18 e 19 há intercalação de camadas areno-argilosa e arenosa. $\mathrm{Na}$ SEV 11, o material é predominantemente areno-argiloso; já na SEV 8, ocorre o acréscimo de sedimentos arenosos. Contudo, a SEV 14 é a menos resistiva entre o contexto geofísico da área do campus, com valores de $\rho_{\mathrm{a}}$ entre 652$948 \Omega$.m. Essa situação também pôde ser refletida pela SEV 7, nas profundidades inferiores a 2,0 m, apontando para $\rho_{\mathrm{a}} \leq 1.100 \Omega$.m. Segundo Souza et al. (2010), a região do campus sofre influência dos terraços aluvionares dos canais e paleocanais provenientes da microbacia do igarapé Frasco (Figuras 6B e 6C). Logo, a sazonalidade climática proporciona a esta porção da área, e na época de realização do levantamento, o caráter extremamente condutivo, conforme visto nos dados elétricos.

\section{MODELO HIPOTÉTICO GEOELÉTRICO DA PORÇÃO SW DO SABV}

Os ensaios eletrorresistivos efetuados nos entornos dos blocos de Música e de Direito, no Colégio de Aplicação (CAP) e no Centro Amazônico de Fronteira (CAF), designados de padrões 5 e 7, mostram-se amplamente distribuídos no campus (NW, NE, SE e SW) (Figura 4), contudo, configuraram zonas permoporosas com pouco potencial aquífero, pois apontam para maior predominância de materiais argilosos, os quais podem funcionar como camada selante, protegendo a possível zona detentora de água da contaminação superficial, uma vez que mostram espraiamento desse conteúdo litológico na profundidade de 3,2-13 m (Figuras 8A e 8B).

Já os padrões 2, 4 e 6, nas porções NW, centrooeste, norte e NE, executados nas imediações do Bloco VII, centros de convivência e o de Ciências e Tecnologia (CCT) (Figura 4), são as zonas de moderada expressividade, pois detêm possível presença de materiais areno-argilosos e/ou argilo-arenosos desde aproximadamente os $4 \mathrm{~m}$ de profundidade, tendo maior concentração no intervalo de 5-13 m (Figura 8). Os padrões 1 e 3, porções SW e WNW, próximos ao Complexo do Insikiran e do Bloco I (Figura 4), configuraram-se como as melhores evidências de zonas permoporosas da área, devido aos indícios de concentrações lateríticas porosas e, ainda, em virtude de apresentarem caráter extremamente arenoso, mostrando-se intensamente distribuídos tanto nas metragens iniciais, bem como além dos $13 \mathrm{~m}$ de profundidade (Figuras 8).

\section{CONCLUSÃO}

O estudo geofísico executado na faixa sudoeste do Sistema Aquífero Boa Vista, no campus Paricarana, da UFRR, possibilitou tecer inferências relacionadas à subsuperfície no que se refere ao comportamento elétrico do conteúdo litológico da Formação Boa Vista (i. e., arenitos, argilitos e concreções lateríticas ferruginosas) e dos depósitos coluvionares e aluvionares do Quaternário, embora estes últimos não exerçam papel importante no aquífero. Constatou-se, assim, que a porção sudoeste do SABV possui as zonas permoporosas mais significantes para a locação de poços tubulares, localizadas nas regiões WNW e SW do campus Paricarana. É importante ressaltar que estas, apesar de representarem as melhores potencialidades aquíferas, já mostram indícios pontuais e visíveis de possível contaminação superficial, a exemplo do restaurante universitário. O mau cheiro exalado, advindo das caixas de gordura e das fossas sépticas construídas de forma equivocada, dá a esta zona, mesmo que de forma pontual, caráter disseminador para o contaminante, pois a alta porosidade do material (arenoso) facilitará a percolação dos fluídos em direção às zonas detentoras de água subterrânea. Portanto, sugere-se que, caso seja construído um poço tubular nesta região, este deve ter profundidade superior a $20 \mathrm{~m}$ e afastamento lateral de agentes contaminantes com, ao menos, $50 \mathrm{~m}$.

O relevo plano na região do campus e os valores de resistividade elétrica aparente evidenciaram que os menores relevos (confluência de rios) estão associados, na maioria das vezes, às porções que retrataram os 


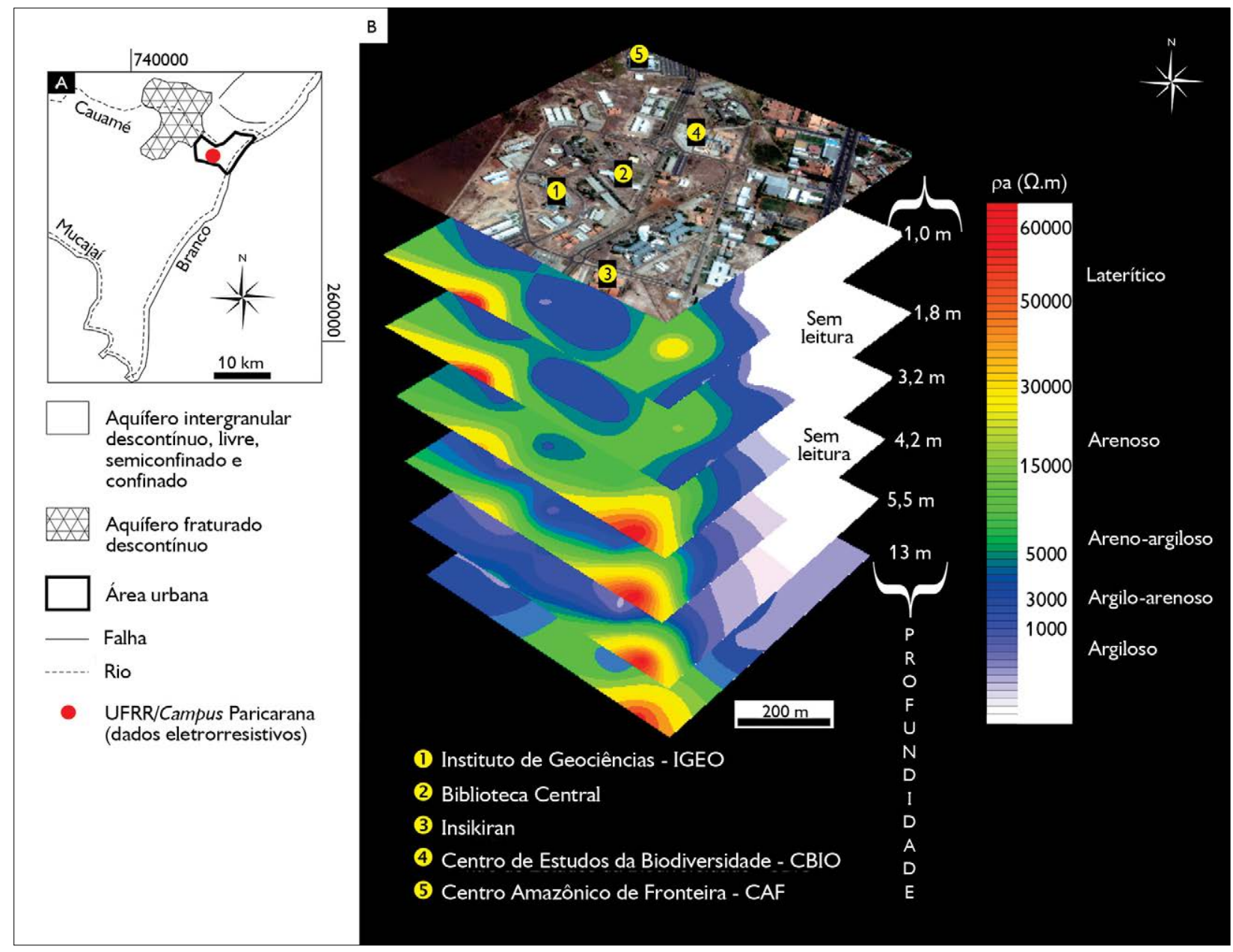

Figura 8. Modelo hipotético do SABV (porção sudoeste): A) Sistema Aquífero Boa Vista (modificado de Wankler et al., 2012); B) curvas de isovalores mostrando a variação das zonas permoporosas em profundidade.

baixos valores de resistividade. Estas regiões com leves declives também se relacionam aos paleolagos e aos lagos sazonais, localizados nas porções NE-SE e a NW do campus. É visível que estes lagos ainda sofrem a influência da microbacia do igarapé Frasco, a qual é abastecida pelo rio Cauamé, e consequentemente propiciam a alimentação das zonas permoporosas na área de estudo. Em períodos chuvosos, as porções de menor elevação tornam-se saturadas e o nível freático fica extremamente próximo à superfície, podendo aflorar, enquanto nos períodos secos o nível freático encontra-se entre 3,03,5 $\mathrm{m}$ de profundidade.
A conexão de diversas metodologias na pesquisa tem se mostrado eficaz nos estudos ambientais. Assim, o uso do produto das imagens de sensoriamento remoto, associado aos dados geológico e geofísico, permitiu configurar as zonas permoporosas sudoeste do SABV, mesmo que este ainda esteja em fase de delimitação no estado de Roraima. Destaca-se, ainda, que a presente pesquisa tem caráter inédito no estado, tornando-se necessária sua continuidade, pois a metodologia geofísica empregada apresenta baixo custo operacional e tempo de resposta imediato, permitindo-se, assim, mapear e compreender melhor o aquífero.

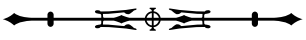




\section{AGRADECIMENTOS}

Ao Instituto de Geociências da UFAM, em nome do professor Dr. João da Silva Carvalho, por ceder o resistivímetro Megger Biddle 63241 Earth Tester. À professora Maria Lorena Malta Feitoza e aos graduandos, Ana Paula Gauger, Fernando Guareschi, Guilherme de Andrade Gonzaga e Thiago Falcão Soares, do curso de Geologia da UFRR, pelo auxílio nas etapas de campo.

\section{REFERÊNCIAS}

AGÊNCIA NACIONAL DE ÁGUAS (ANA), 2013. Água e desenvolvimento sustentável: recursos hídricos fronteiriços e transfronteiriços do Brasil: 1-140. Secretaria de Assuntos Estratégicos Presidência da República (Série de Estudos Estratégicos), Brasília.

ÁVILA, I. C. S. S., 2007. Caracterização preliminar do subsolo da área urbana de Boa Vista-RR, a partir de sondagens de simples reconhecimento: 1-91. Dissertação (Mestrado em Recursos Naturais) - Universidade Federal de Roraima, Boa Vista.

BESERRA NETA, L. C. \& S. S. TAVARES JUNIOR, 2008. Geomorfologia do estado de Roraima por imagens de sensores remotos. In: P. R. F. SILVA \& R. S. OLIVEIRA (Org.): Roraima 20 anos: as geografias de um novo Estado: 168-192. EdUFRR, Boa Vista.

BRAGA, A. C. O., 2016. Geofísica aplicada: métodos geoelétricos em hidrogeologia: 1-159. Oficina de Texto, São Paulo.

COMPANHIA DE PESQUISAS DE RECURSOS MINERAIS (CPRM), 2002. Zoneamento ecológico econômico da região central do estado de Roraima. CPRM/Serviço Geológico do Brasil, Rio de Janeiro.

ELLERT, N., 2013. Prospecção geofísica. In: C. E. Q. GIAMPÁ \& V. G. GONÇALES (Ed.): Águas subterrâneas e poços tubulares profundos: 2. ed.: 145-168. Oficina de Texto, São Paulo.

GALLAS, J. D. F., 2003. Prospecção de água subterrânea em aquíferos cristalinos com o emprego de métodos indiretos. Revista do Instituto Geológico 24(1-2): 43-45. DOI: http://dx.doi. org/10.5935/0100-929X.20030004.

GROTZINGER, J. \& T. H. O. JORDAM, 2013. Para entender a Terra: 6 ed.: 1-694. Ed. Bookman, Porto Alegre.

KEAREY, P., M. BROOKS \& I. HILL, 2009. Levantamento elétrico. In: P. KEAREY, M. BROOKS \& I. HILL (Ed.): Geofísica de exploração: 1 ed.: 315-353. Oficina de Textos, São Paulo.

LABORATÓRIO DE MÉTRICAS DA PAISAGEM (MEPA), [s. d.]. Disponível em: <http://ufrr.br/mepa/>. Acesso em: 15 setembro 2014.
LIMA, J. A., M. V. R. DAMBROS, M. A. P. M. ANTONIO, J. G. JANZEN \& M. MARCHETTO, 2011. Potencial da economia de água potável pelo uso de água pluvial: análise de 40 cidades da Amazônia. Engenharia Sanitária e Ambiental 16(3): 291-298. DOI: http://dx.doi.org/10.1590/S1413-41522011000300012.

MADRUCCI, V., F. TAIOLI \& C. C. ARAÚJO, 2005. Análise integrada de dados de sensoriamento, geologia e geofísica no estudo de aquífero fraturado, Lindóia-SP. Revista Brasileira de Geofísica 23(4): 437-451. DOI: http://dx.doi.org/10.1590/50102261X2005000400007.

MAY, S., 2004. Estudo da viabilidade do aproveitamento de água de chuva para consumo não potável em edificações: 1-189. Dissertação (Mestrado em Engenharia da Construção Civil) Universidade de São Paulo, São Paulo.

MENDES, R. L. R. \& O. P. VERMA, 2002. Prospecção de água subterrânea na região de Belém (PA) através de perfilagem geofísica de poço e eletrorresistividade. Revista Brasileira de Geociências 32(1): 8-94.

NERES, W. C. B. \& F. L. WANKLER, 2012. Análise do Sistema Aquífero Boa Vista na região do município de Boa Vista. Anais do Encontro do Programa de Iniciação Científica 11: 1 CD-ROM.

PARASNIS, D. S., 1971. Geofisica minera: 1-375. Paraninfo, Madrid.

PARASNIS, D. S. \& E. ORELLANA, 1970. Princípios de geofísica aplicada: v. 1: 1-208. Paraninfo, Madrid.

PINTO, V. M., C. A. BICUDO, M. A. BRANDÃO \& P. E. BORGES, 2012. O contexto geológico no município de Boa Vista, Roraima, Brasil. ACTA Geográfica 6(12): 7-19. DOI: http://dx.doi. org/10.5654/actageo2012.0612.0001.

REBOUÇAS, A. C., 2013. Águas subterrâneas. In: C. E. O. GIAMPÁ \& V. G. GONÇALES (Ed.): Aguas subterrâneas e poços tubulares profundos: 2. ed.: 17-56. Oficina de Texto, São Paulo.

REIS, N. J., L. M. FRAGA, M. S. G. FARIA \& M. E. ALMEIDA, 2003. Geologia do estado de Roraima, Brasil. In: F. ROSSI, L. JEAN-MICHEL \& M. L. VASQUEZ (Ed.): Géologie de La France: v. 2-4: 121-134. Ed. Brgm, Paris.

SOUZA, L. S. B., 2010. Evidências tectônicas no leste da llha do Marajó: integração de dados morfoestruturais e geofísicos: 1-202. Tese (Doutorado em Geoquímica e Geotectônica) - Universidade de São Paulo, São Paulo.

SOUZA, L. S. B., D. F. ROSSETTI \& V. R. ELIS, 2013. Neotectonics in Marajó Island, state of Pará (Brazil) revealed by vertical electric sounding integrated with remote sensing geological data. Anais da Academia Brasileira de Ciências 85: 73-86. DOI: http://dx.doi. org/10.1590/S0001-37652013000100006. 
SOUZA, L. S. B. \& O. P. VERMA, 2005. Mapeamento de aquíferos na cidade de Manaus/AM (zonas norte e leste) através de perfilagem geofísica de poço e sondagem elétrica vertical. Revista de Geologia (Fortaleza) 18(2): 227-243.

SOUZA, V., S. S. TAVARES JÚNIOR \& J. R. OLIVEIRA, 2010. Atlas hidrográfico da cidade de Boa Vista, Roraima: 1-62. UFRR, Boa Vista.

SUGUIO, K., 1980. Rochas sedimentares: propriedades, gênese, importância e economia: 1-500. Blücher, São Paulo.

TUCCI, C. E. M., 2008 Águas urbanas. Estudos Avançados 22(63): 97-112. DOI: http://dx.doi.org/10.1590/S010340142008000200007.
U. S. GEOGICAL SURVEY (USGS), [s. d.]. Earth Explorer. Disponível em: <https://earthexplorer.usgs.gov/>. Acesso em: 15 setembro 2014.

VAZ, P. T., J. R. WANDERLEY FILHO \& G. V. BUENO, 2007. Bacia do Tacutu. Boletim de Geociências da PETROBRAS 15(2): 289-297.

WANKLER, F. L., R. A. O. EVANGELISTA \& C. SANDER, 2012. Sistema Aquífero Boa Vista: "estado de arte" do conhecimento e perspectivas. ACTA Geográfica 6(12): 21-39. DOI: http://dx.doi. org/10.5654/actageo2012.0612.0002. 
